\title{
Investor Inattention and the Market Impact of Summary Statistics*
}

\author{
Thomas Gilbert, Shimon Kogan, Lars Lochstoer, \\ and Ataman Ozyildirim ${ }^{\dagger}$
}

August 3, 2007

\begin{abstract}
Investors with limited attention have an incentive to focus on summary statistics rather than individual pieces of information. We use this observation to form a test of the impact of limited attention on the aggregate stock market. We examine the market response to a macro economic release that is purely a summary statistic, the U.S. Leading Economic Index (LEI). Consistent with the limited attention hypothesis, we show that the LEI announcement has an impact on aggregate stock returns, return volatility, and trading volume. Furthermore, we find that the response to the LEI is higher for stocks which inattentive investors are more likely to trade.
\end{abstract}

${ }^{*}$ We would like to thank the Conference Board for providing us with the data. We wish to thank Frank Tortorici and Ken Goldstein for their help, as well as Francisco Gomes, Rick Green, Terry Hendershot, Rich Lyons, Chris Malloy, Christophe Pérignon, and Miguel Palacios for helpful comments. We thank seminar participants at EFMA 2006, Carnegie Mellon, Berkeley, and Penn State. The views expressed in this paper are those of the authors and do not necessarily represent those of The Conference Board. All errors remain ours.

${ }^{\dagger}$ Affiliations: Haas School of Business at UC Berkeley, Tepper School of Business at Carnegie Mellon University, London Business School, and The Conference Board, respectively. Corresponding author: Shimon Kogan, 5000 Forbes Ave, Pittsburgh, PA 15213. E-mail: kogan@andrew.cmu.edu 


\section{Introduction}

For most investors, the costs of processing all relevant information are prohibitively high. As such, these investors can be viewed as having limited attention. Previous studies provide evidence suggesting that investors' limited attention is important for the pricing of individual securities (see, e.g., DellaVigna and Pollet (2006), Hirshleifer, Lim and Teoh (2006), Huberman and Regev (2001)). In this paper, we ask whether limited attention also has an impact on the aggregate stock market.

To answer this question, we examine how the release of summary statistics affect the market. Barberis and Schleifer (2003) and Peng and Xiong (2006) highlight that investors with limited attention economize on information processing by grouping stocks into categories. In the same spirit, investors with limited attention may choose to focus on summary statistics instead of attending to every individual piece of information. This implication of limited attention has not, to our knowledge, been tested in the previous literature.

The summary statistic we identify is the Conference Board's U.S. Leading Economic Index (LEI). This index is designed to track business cycle fluctuations and signal turning points in the business cycle. Thus, it is economically relevant as it contains information about future cash flows and discount rates, and it has a leading relationship relative to macroeconomic aggregates such as output and employment. Importantly, the index aggregates data that is already publicly available and is released monthly on a pre-determined day at a pre-determined time.

Our null hypothesis is that there should be no market reaction to the announcements of the index since 1) the LEI is based on previously released data, 2) the components and methodology of the LEI are readily available to the public, and 3) the index is fairly easy to reproduce. These are well-known facts, publicized among other places on the Conference Board's internet page and Bloomberg. ${ }^{1}$ Thus, it is possible to calculate the change in the index before its release. However, if limited attention is important for the aggregate stock market, the information in the LEI would be news to investors and as such have a market impact. Further, if this market impact is caused by limited attention, we would expect to find a larger response among stocks in which investors subject to this bias are more likely to trade.

Looking at intraday data over 72 announcement days over the period 1997-2005, we find

\footnotetext{
${ }^{1}$ See http://www.conference-board.org/economics/bci/general.cfm and http://www.bloomberg.com/markets/ecalendar/index.html
} 
that the release of the LEI is associated with measures of information arrival such as market returns, return volatility, and trading volume. The market return is positively related to the changes in the LEI; a one standard deviation increase in the LEI on average leads to a 3.5 basis-point increase in the subsequent 5-minute market returns. Aggregate return volatility and trading volume increase by $25 \%$ and $7 \%$, respectively, following the announcement. The volatility increase is significant for the 5-minute interval following the announcement, while the volume increase persists for the subsequent 30 minutes.

The absolute level of the return response is fairly low. However, this result is expected given that limited attention should affect markets less if the information is market-wide, as is the case here (see Peng and Xiong (2006)); investors have a higher incentive to be attentive to information that is more important for their utility, and as a group investors therefore focus more on market-wide information. Further, since the release is recurring and replicable, one would expect attentive arbitrageurs to eliminate profit opportunities arising from the release up to transaction costs. Therefore, the tests in this paper are stacked against the limited attention alternative hypothesis. Our results are thus consistent with both limited attention on the part of a subset of market participants and market efficiency imposed by information gathering incentives and arbitrageurs.

To examine the robustness of the results we test another hypothesis. If the market impact of the LEI announcements are caused by limited attention of a subset of investors, we would expect to find a larger impact on stocks which investors subject to this bias are likely to trade. We test this conjecture by looking at the cross-sectional return response to the LEI release. Inattention-prone investors are more likely to trade large capitalization stocks, which have high volume and are featured more in the news, as noted by Barber and Odean (2005), and 'glamour stocks' (see Lakonishok, Shleifer and Vishny (1994)), which have high market to book ratios. Thus, limited attention suggests that large and high book to market stocks should respond more strongly to the release of the LEI. We construct intraday returns for the 25 Fama-French portfolios on the announcement days and show that, consistent with the limited attention effect, the returns of large and low book-to-market stocks respond more to the LEI announcements, compared to small capitalization and high book-to-market stocks.

The paper proceeds as follows. Section 2 describes the data we use in this paper. Section 3 presents the aggregate stock market results, while Section 4 presents the cross-sectional results. We conclude in Section 5 . 


\section{The Data}

In this study, we combine three different data sources: macro news, intraday index prices and individual stock transactions. The LEI release dates and index series were provided by The Conference Board. It is important to note that we use the original release series which were available to investors at the time since subsequent revisions to macro data resulted in ex-post updates of the index. In our sample (1/1997 - 8/2005), the index is always reported at 10:00am. ${ }^{2}$ The market returns data are constructed using S\&P500 future prices, while the cross-sectional analysis uses individual stock transactions data from the TAQ database. The futures data were purchased from Price-Data.com and includes five minute interval data on open, high, low and close prices for each of the futures contacts traded between 1997 and 2005. ${ }^{3}$ For each date, we determined which of the multiple contracts available are "on the run" by comparing their daily volume. The intraday return series for each day were calculated using prices from that day's "on the run" contract. Since aggregate intraday volume data were not readily available, we constructed them by gathering tick-by-tick data from TAQ for all firms that were in the S\&P500 index on a given day. We added transactions across all firms for each 5 minute interval to arrive at the market volume for that time period.

In addition, we use data from the Census Bureau, Bureau of Economic Analysis (BEA), Federal Reserve Board (FRB), National Association of Purchasing Managers (NAPM), and Conference Board, to screen out all dates on which other macro announcements were released between 9:30am and 10:30am. Specifically, we screen out dates on which one of the following announcements were made: New Home Sales, Durable Goods Orders, Factory Orders, Construction Spending, Business Inventories, Consumer Confidence Index, NAPM Index and Target Federal Funds Rate. These announcements were identified by Anderson et al. (2005) as being most important for U.S. equity returns. ${ }^{4}$

\subsection{The Leading Economic Index}

The Composite Index of Leading Economic Indicators (LEI), calculated and published monthly by The Conference Board (TCB), is designed to predict turning points (peaks and troughs) in the business cycle. TCB took over the responsibility to publish and maintain

\footnotetext{
${ }^{2}$ Before 1997, the index was reported at 8:30am, which coincides with the reporting time for a number of other macro economic releases (e.g., Census Bureau, Bureau of Economic Analysis). The move to the 10:00am announcement time reflected in part a desire to make the announcement during market open hours.

${ }^{3}$ Other data fields includes trading volume and open interests.

${ }^{4}$ See Table 4 in Anderson et. al. (2005).
} 
the LEI and the Business Cycle Indicators database from the Bureau of Economic Analysis (U.S. Department of Commerce, BEA) starting with the December 6, 1995 release.

Leading indicators are high frequency series that have an established tendency to decline before recessions and rise before recoveries (for more details on the indicator approach to measuring and analyzing business cycles see Burns and Mitchell (1946) and Zarnowitz (1992)). ${ }^{5}$ For instance, new orders for machinery and equipment are placed well before investment plans are completed. By design, the LEI should help predict changes in real economic activity. Figure 1 shows that the LEI systematically declines ahead of the recessions dated by the NBER. Filardo (2004) provides evidence that the LEI performs well as a variable to forecast cyclical movements in the economy. McGuckin et al. (2007) also report evidence on the significant out-of-sample forecasting ability of the LEI.

After The Conference Board assumed responsibility for the Business Cycle Indicators program, it reviewed and revised the LEI in 1996. Notably, the composition of the LEI was changed: two components were deleted due to their excessive volatility which led to "false signals" of recessions and a new component was added (the Interest Rate spread). After this major revision (first released December 30, 1996), The Conference Board also started to publish the LEI press release at 10:00am EST to be consistent with its other economic data releases. Previously, the LEI releases were made at 8:30am, following the BEA schedule.

In the current indexing methodology, which changed very little since the 1960s when the U.S. Department of Commerce began publishing composite indexes, the volatility of each component is standardized before the component contributions are averaged together, using equal weights. This adjustment is made so that relatively more volatile series do not exert undue influence on the index (the standardization factors are updated every year in January and are available in the monthly press releases). The average contribution becomes the monthly change in the LEI. Using this monthly change, the index level is calculated recursively starting from a value of 100 in January 1959, and it is normalized to have an average value of 100 in 1996 .

Seven of the ten indicators used every month in the LEI calculation are available at least 24 hours before each release. The monthly values of the three remaining components which are not available on the publication date are based on estimates by TCB. These components (Manufacturers' New Orders for Consumer Goods and Materials, Manufacturers' New Orders

\footnotetext{
${ }^{5}$ The indicator approach has a long history since the mid-1930s and was developed at the National Bureau of Economic Research (NBER), following the influential work of Wesley C. Mitchell and Arthur F. Burns. It has been a major component of the NBER program in economic growth and fluctuations.
} 


\section{FIGURE 1}

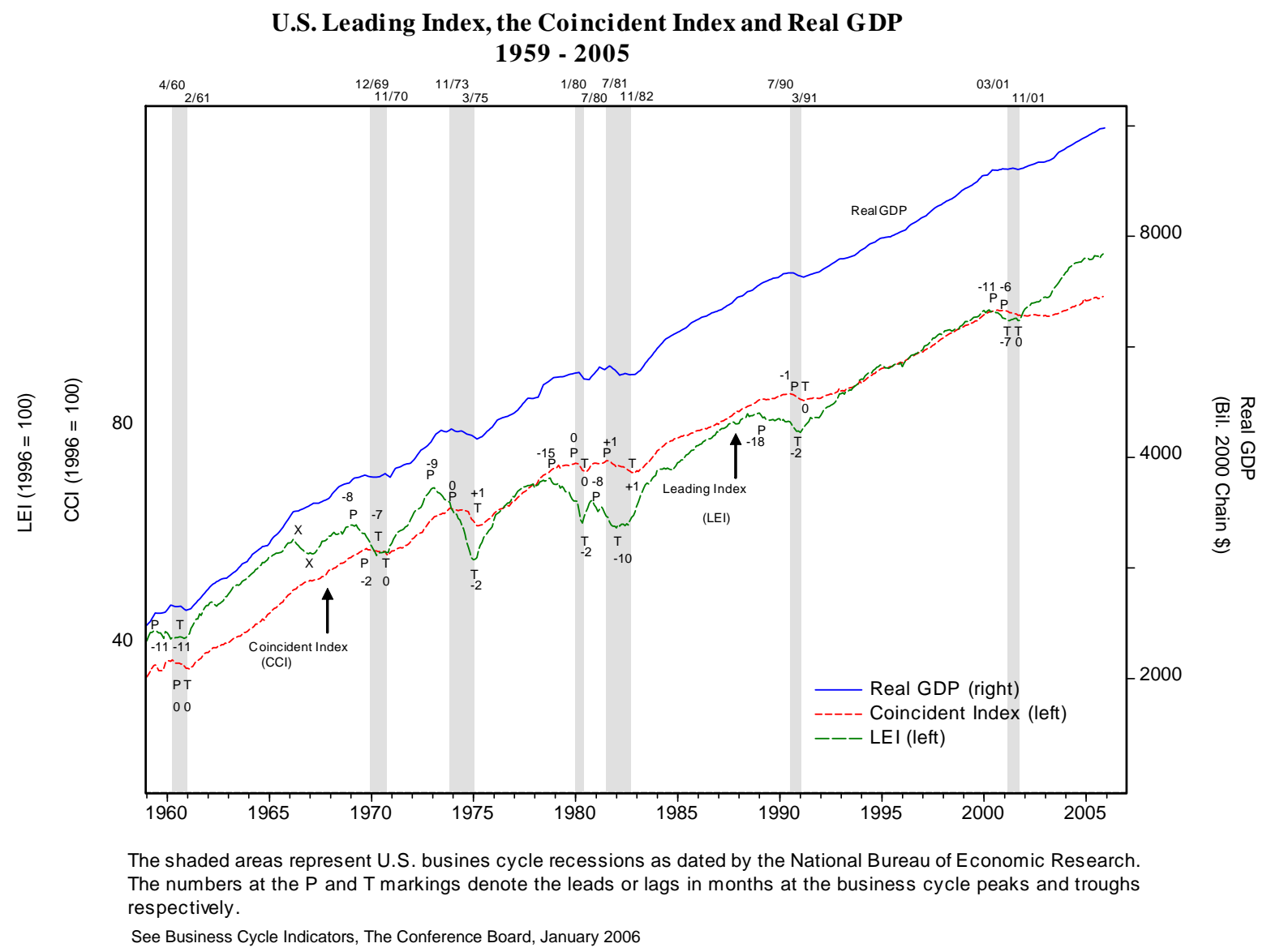

Figure 1: Time series of the Leading Economic Index, the Coincident Index and Real GDP. 
for Nondefense Capital Goods, and the personal consumption expenditure deflator used to get real Money Supply (M2)) are estimated using a simple $\operatorname{AR}(2)$ time series regression. ${ }^{6}$ The Appendix provides more background information and details on why this procedure was selected and how it was implemented by TCB.

\section{Market Level Results}

This section presents the impact of the LEI announcements on aggregate measures of information arrival: stock returns, return volatility and trading volume. Our null hypothesis is that the LEI announcements have no effect. We focus on intraday market activity for two reasons. First, previous research has shown that the effect of news on aggregate stock market prices are mainly manifested in intraday returns data (see Andersen et al. (2003, 2007)). Second, focusing on intraday returns makes our study less sensitive to the presence of other news effects over the same day (including the time from the close the day before) that we may not have captured in our econometric specification. Over the course of any given 24 hour period there is a continuous flow of news. By narrowing the time-window, we minimize the likelihood of the results being contaminated by other, unidentified shocks to investors' information sets.

\subsection{General Methodology}

A first-order concern when evaluating intraday data is the well-known presence of intraday patterns in volatility and volume (e.g., Admati and Pfleiderer (1988)). Rather than attempt a parametric model to describe such intraday patterns, for which at present there is no agreed upon model, we investigate return, volatility and volume patterns on LEI announcement days vs. non-announcement days by utilizing a matching study. This allows us to control for both intraday and day-of-the-week effects. Specifically, we match each announcement date with the one week ahead non-announcement date, unless there was another important macro news release on that date, in which case we picked the date following the LEI release. Out of a total of 104 announcements in our sample (1/1997 - 8/2005), we exclude 30 due to the presence of other simultaneous macro announcements and 2 since the intraday future prices were not available for every 5 minutes in the 9:30-10:30 time interval (see Section 3.5 for results including all announcements days).

\footnotetext{
${ }^{6}$ When the unavailable data become available in the next month, the index is revised.
} 
We evaluate the aggregate return, volatility and volume of announcement days versus non-announcement days over different 5-minute intervals around the time of announcement to investigate dynamic effects. The LEI release is at 10:00 throughout the sample, and we focus on the 9:30 to 10:30 interval. ${ }^{7}$ Anderson et al. (2003) note that looking at 5-minute futures returns strikes a good balance between capturing fundamental dynamics operating at high-frequencies and minimizing the noise in returns caused by bid-ask bounce and other microstructure issues. The futures contracts on the S\&P500 are very liquid, so empirically neither stale prices nor the bid-ask bounce are important issues for our purposes. Further, this approach allows us to compare our results with those obtained in similar studies. For all intervals, we test whether there is a return response at the time of the announcement and whether volatility and volume are different on announcement versus non-announcement days.

\subsection{Returns}

In this section, we investigate the effect of the LEI announcement on S\&P500 futures' returns. We first define the normalized change in the LEI index, $\Delta \overline{L E I}_{t}$, as

$$
\Delta \overline{L E I}_{t} \equiv \frac{\Delta L E I_{-} \text {index }_{t}-E_{T}\left[\Delta L E I_{-} \text {index }_{t}\right]}{\sigma_{T}\left(\Delta L E I_{-}{ }^{\left.i n d e x_{t}\right)}\right.}
$$

where $E_{T}[\cdot]$ and $\sigma_{T}(\cdot)$ denote the sample mean and standard deviation, respectively. We make this normalization for two reasons: 1) it makes the interpretation of regression coefficients more intuitive, and 2) it makes the results easier to compare to related studies where such normalizations are used (such as Andersen et al. (2003) and Lyons and Evans (2005)). ${ }^{8}$ It is usual to subtract the conditional expectation of the release and divide by the standard deviation of the imputed shocks. However, since our index is replicable, there are no well-defined "shocks". Therefore, we simply consider deviations from the sample mean.

We run the regression

$$
R_{i, t}^{A}=\alpha^{A}+\beta_{i}^{A} \Delta \overline{L E I}_{t}+\varepsilon_{i, t}^{A} \quad t \in[1,2, \ldots, T]
$$

where $R_{i, t}^{A}$ is the intraday interval $i$ 's log return on the announcement day $t$. Thus, if the

\footnotetext{
${ }^{7}$ We use the 24:00 time convention when quoting time intervals. Thus, 10:00 is 10:00am.

${ }^{8}$ Note that because the sample means and standard deviations are constants, this normalization does not affect the statistical significance of the estimated response coefficients.
} 
TABLE 1

Return Regressions

$$
R_{i, t_{0}-t_{1}}=\alpha_{i}+\beta_{i} \Delta \overline{L E I}_{t}+\varepsilon_{i, t}
$$

\begin{tabular}{|c|c|c|c|c|c|c|c|c|}
\hline \multirow{2}{*}{$\begin{array}{l}\text { Time } \\
t_{0}-t_{1}\end{array}$} & \multicolumn{4}{|c|}{ Announcement Days } & \multicolumn{4}{|c|}{ Non-Announcement Days } \\
\hline & $\begin{array}{c}\alpha \\
(s . e .)\end{array}$ & $\begin{array}{c}\beta \\
(s . e .)\end{array}$ & $R^{2}$ & $p-v a l$ & $\begin{array}{c}\alpha \\
(s . e .)\end{array}$ & $\begin{array}{c}\beta \\
(s . e .)\end{array}$ & $R^{2}$ & $p-v a l$ \\
\hline $9: 30-9: 35$ & $\begin{array}{l}-.0047 \\
(.0147)\end{array}$ & $\begin{array}{c}.0180 \\
(.0160)\end{array}$ & $2.09 \%$ & 0.26 & $\begin{array}{l}-.0176 \\
(.0154)\end{array}$ & $\begin{array}{c}.0021 \\
(.0132)\end{array}$ & $0.03 \%$ & 0.87 \\
\hline $9: 35-9: 40$ & $\begin{array}{c}.0073 \\
(.0146)\end{array}$ & $\begin{array}{c}.0257^{*} \\
(.0133)\end{array}$ & $4.19 \%$ & 0.06 & $\begin{array}{l}-.0166 \\
(.0182)\end{array}$ & $\begin{array}{c}.0285 \\
(.0194)\end{array}$ & $3.34 \%$ & 0.15 \\
\hline $9: 40-9: 45$ & $\begin{array}{l}.0115 \\
(.0136)\end{array}$ & $\begin{array}{c}-.0144 \\
(.0132)\end{array}$ & $1.57 \%$ & 0.28 & $\begin{array}{l}-.0195 \\
(.0189)\end{array}$ & $\begin{array}{c}.0178 \\
(.0181)\end{array}$ & $1.24 \%$ & 0.33 \\
\hline $9: 45-9: 50$ & $\begin{array}{c}.0148 \\
(.0159)\end{array}$ & $\begin{array}{c}.0084 \\
(.0168)\end{array}$ & $0.39 \%$ & 0.62 & $\begin{array}{l}-.0137 \\
(.0173)\end{array}$ & $\begin{array}{l}-.0081 \\
(.0188)\end{array}$ & $0.31 \%$ & 0.67 \\
\hline $9: 50-9: 55$ & $\begin{array}{l}.0125 \\
(.0145)\end{array}$ & $\begin{array}{l}-.0147 \\
(.0152)\end{array}$ & $1.43 \%$ & 0.34 & $\begin{array}{c}.0086 \\
(.0176)\end{array}$ & $\begin{array}{l}-.0087 \\
(.0199)\end{array}$ & $0.34 \%$ & 0.66 \\
\hline $9: 55-10: 00$ & $\begin{array}{c}.0272 \\
(.0150) \\
\end{array}$ & $\begin{array}{c}.0038 \\
(.0166) \\
\end{array}$ & $0.09 \%$ & 0.82 & $\begin{array}{l}-.0033 \\
(.0150)\end{array}$ & $\begin{array}{c}.0125 \\
(.0137) \\
\end{array}$ & $0.97 \%$ & 0.36 \\
\hline $10: 00-10: 05$ & $\begin{array}{c}-.0437^{* *} \\
(.0176) \\
\end{array}$ & $\begin{array}{l}.0351^{* *} \\
(.0162) \\
\end{array}$ & $5.33 \%$ & 0.03 & $\begin{array}{l}-.0232 \\
(.0165) \\
\end{array}$ & $\begin{array}{c}.0072 \\
(.0177) \\
\end{array}$ & $0.26 \%$ & 0.69 \\
\hline $10: 05-10: 10$ & $\begin{array}{l}-.0162 \\
(.0152)\end{array}$ & $\begin{array}{l}-.0085 \\
(.0153)\end{array}$ & $0.44 \%$ & 0.58 & $\begin{array}{c}.0264 \\
(.0134)\end{array}$ & $\begin{array}{c}.0019 \\
(.0129)\end{array}$ & $0.03 \%$ & 0.89 \\
\hline $10: 10-10: 15$ & $\begin{array}{l}-.0185 \\
(.0159)\end{array}$ & $\begin{array}{l}-.0090 \\
(.0184)\end{array}$ & $0.45 \%$ & 0.63 & $\begin{array}{l}.0001 \\
(.0170)\end{array}$ & $\begin{array}{l}.0040 \\
(.0152)\end{array}$ & $0.08 \%$ & 0.80 \\
\hline $10: 15-10: 20$ & $\begin{array}{l}-.0213 \\
(.0138)\end{array}$ & $\begin{array}{l}-.0125 \\
(.0117)\end{array}$ & $1.15 \%$ & 0.29 & $\begin{array}{c}-.0291^{* *} \\
(.0140)\end{array}$ & $\begin{array}{l}.0025 \\
(.0150)\end{array}$ & $0.05 \%$ & 0.87 \\
\hline $10: 20-10: 25$ & $\begin{array}{l}-.0377 \\
(.0146)\end{array}$ & $\begin{array}{l}-.0020 \\
(.0144)\end{array}$ & $0.03 \%$ & 0.89 & $\begin{array}{l}-.0225 \\
(.0154)\end{array}$ & $\begin{array}{l}-.0163 \\
(.0160)\end{array}$ & $1.57 \%$ & 0.31 \\
\hline $10: 25-10: 30$ & $\begin{array}{c}-.0306^{* *} \\
(.0136)\end{array}$ & $\begin{array}{l}-.0001 \\
(.0119)\end{array}$ & $0.00 \%$ & 0.95 & $\begin{array}{l}.0035 \\
(.0161)\end{array}$ & $\begin{array}{l}-.0044 \\
(.0117)\end{array}$ & $0.11 \%$ & 0.71 \\
\hline
\end{tabular}

Table 1: The Table reports estimates from OLS regressions of S\&P500 futures return on the sameday normalized LEI announcement for announcement days, and matched LEI announcement for non-announcement days. There are 72 observations in each group. Returns are multiplied by 100, standard errors are corrected for heteroskedasticity (White standard errors). The changes in the LEI index have been normalized to have mean zero and unit variance. One asterisk denotes sigifnicant at the 10 percent level, while two asterices denotes significant at the 5 percent level in a two-tailed test. 
interval $i$ is before 10:00, the regressor is the same-day future percentage change in the LEI index, whereas if the interval $i$ is after 10:00, the regressor is the same day's already reported LEI change. For comparison, we also run the regression

$$
R_{i, t^{\prime}}^{N A}=\alpha^{N A}+\beta_{i}^{N A} \Delta \overline{L E I}_{t}+\varepsilon_{i, t^{\prime}}^{N A} \quad t^{\prime} \in[1,2, \ldots, T]
$$

where the superscript ${ }^{N A}$ refers to the non-announcement day $t^{\prime}$, which corresponds to the matched announcement day $t$. Table 1 presents the results.

The regression coefficients for the 5-minute intervals before the announcement (from 9:30 - 10:00) are on average positive, but insignificant. The regression coefficients on nonannouncement days are also insignificant and on average half as big as the case for the announcement days. At the announcement (interval 10:00 - 10:05), the announcement day regression coefficient is positive and significant at the $5 \%$ level, while the non-announcement day regression coefficient is about a quarter in magnitude and insignificant. Thus, the LEI announcement is moving aggregate stock prices in the direction of the change in the LEI index: A one standard deviation change in the LEI on average gives a 3.5bp return response on the S\&P500 futures. Over the remaining 25 minutes of the event window, there are no significant effects. However, all the announcement day regression coefficients are negative, indicating that prices revert somewhat after the initial reaction at 10:00. For the non-announcement days, there are no significant effects and the average of the regression coefficients is essentially zero.

\subsubsection{Economic Significance}

Benchmarking Against Major Macro News Announcements. The return response documented in the previous section may seem small in magnitude. However, when compared to major macro economic news announcements such as Non-Farm Payroll and New Home Sales, the response is economically significant. Figure 2 shows the response of 5 -minute returns to the LEI announcement next to the statistically significant 5-minute return responses to macro economic news announcements taken from Andersen et al. (2005). ${ }^{9}$ As Figure 2

\footnotetext{
${ }^{9}$ Andersen et al. (2007) investigate all macro releases including the LEI, but do not find significant evidence that it has a price impact. We offer two explanations for the discrepancy between our results. First, in their table 4, they state that the LEI is released at 8:30am. This is true only for the beginning of their sample. In our sample, from 1997 and onwards, the release time is always at 10:00am. At present we do not know if the authors corrected the change in release time over the sample, but they give no indication in their paper that they do. Second, and more fundamentally, they investigate normalized "surprises" based on market estimates obtain from a survey database (MMS). But, as we discussed in section 3, it is unclear
} 
FIGURE 2

LEI Return Response: Benchmark Against Major US Macro Releases

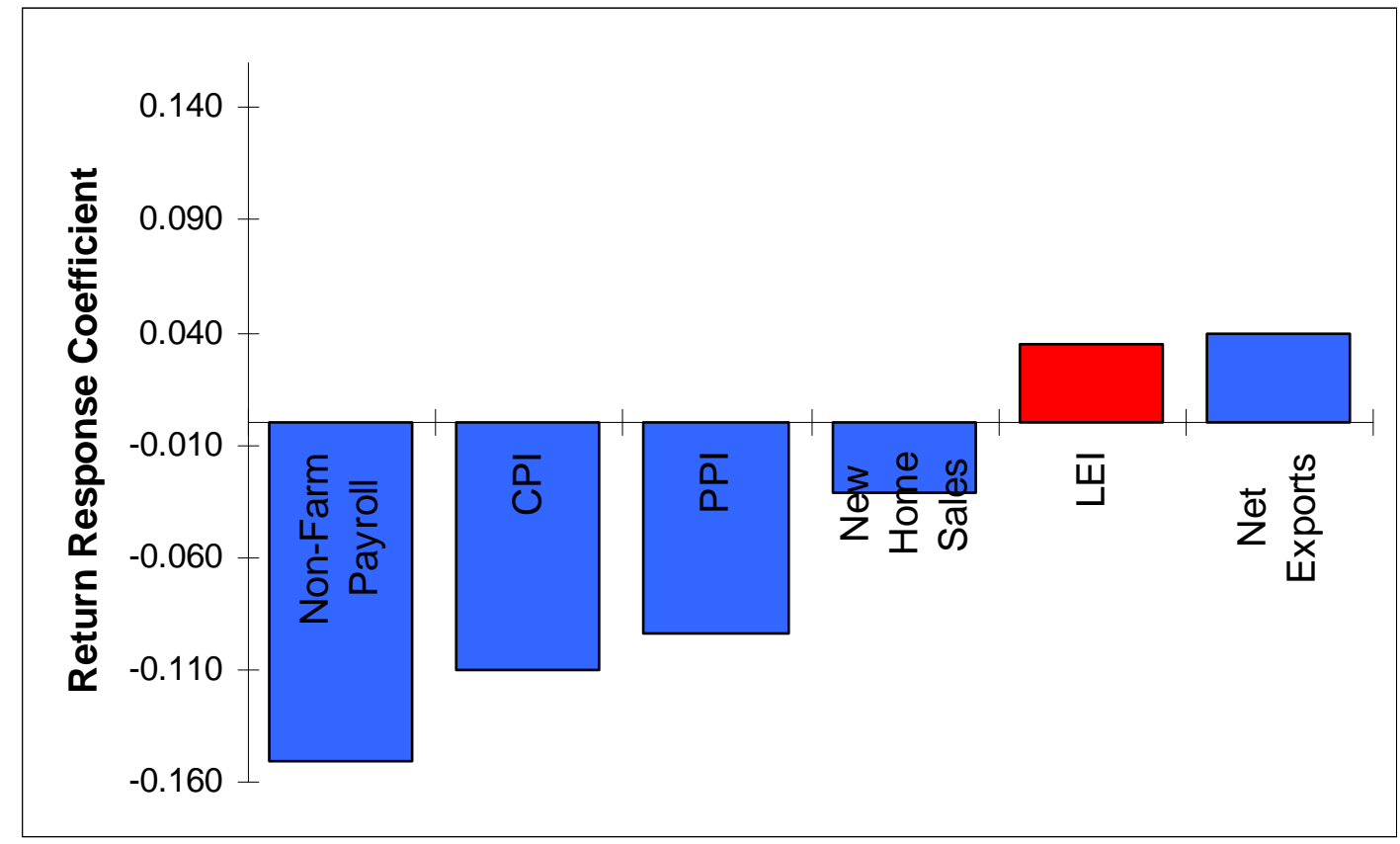

Figure 2: This Figure shows the 5 minute return response to normalized (mean zero, unit variance) macro economic news announcements (Andersen et al. (2007)) next to the 5 minute return response to the normalized LEI announcement.

shows, the response to the LEI announcement is as big as for true news announcements such as New Home Sales and Net Exports. It is about 30\% of the CPI announcement and $25 \%$ of the macro economic announcement that gives the largest return response (Non-Farm Payroll).

Cumulative Returns Assessment. To further assess the economic significance of the return-predictability, we construct a simple trading strategy based on the change in the LEI index. The strategy initiates a buy (sell) of S\&P 500 index futures at the open prices on the day of the announcement in the direction of the change in the index. The amount transacted is proportional to the absolute value of the (known) change, maxed out at 0.4 . Therefore, if the change in the LEI index on date $t$ is 0.2 , the strategy initiates a buy of $\$ 0.2$. At 10:05, the position is reversed.

Notice that this is a conservative strategy. An alternative, more aggressive strategy, would initiate the trades immediately before 10:00 and reverse them at 10:05, resulting in what these "shocks" represent since the index is perfectly forecastable. 
lower volatility of profits. Further, volume at the open and right after the announcement is relatively high so there is good reason to believe that these hypothetical trades might have been feasible. At the same time, we do not claim that in practice this strategy would have been profitable as we do not account for trading costs. The purpose of this exercise is simply to obtain a measure of the economic size of the apparent informational inefficiency.

Aggregating the results across the 72 observations, we find that the strategy yields a cumulative return of $1.87 \%$ with corresponding standard deviation of $9.7 \%$, while the results obtained from running the same hypothetical trades on the matching non-announcement days yield a cumulative return of $0.7 \%$ and standard deviation of $9.6 \%{ }^{10}$ Therefore, the Sharpe ratio obtained from announcement days is at least 2.4 times the Sharpe ratio obtained from trading on matched non-announcement days.

\subsection{Volatility}

In this section, we test whether 5 -minute stock return volatility is higher on announcement days compared to non-announcement days in each of the 5-minute intervals in the hour around the announcement.

As mentioned, it is well-documented that aggregate stock return volatility is time-varying. To control for this, we employ a matching study. First, we calculate the volatility of 5-minute returns for each non-announcement day for the relevant trading hour. Next, we divide the 5-minute returns on both the corresponding announcement day and the non-announcement day by this volatility measure. ${ }^{11}$ We use only the non-announcement days' volatility in order to capture any overall higher levels of volatility on announcement days in the subsequent volatility tests. This normalization is valid under the null hypothesis that the volatility over matched announcement and non-announcement days are equal.

Next, we calculate the volatility of 5 -minute (normalized) announcement and non-announcement day returns for each interval as follows. Let $\tilde{R}_{i, t}$ be the normalized 5 -minute log return for the interval $i$, where we have $i \in\{9: 30-9: 35,9: 35-9: 40, \ldots, 10: 25-10: 30\}$. Interval $i$ 's variance estimate is then

$$
\hat{\sigma}_{i}^{2}=\frac{1}{T} \sum_{t=1}^{T} \tilde{R}_{i, t}^{2}
$$

\footnotetext{
${ }^{10}$ These figures represent 35-minute return (9:30-10:05) accumulated over 72 days.

${ }^{11}$ We calculate standard deviations assuming the expected 5 -minute returns are equal to zero. This is a standard assumption given the short time-interval and yields more robust volatility estimates. Using the residuals of a regression of intraday returns on their lagged value (to capture any bid-ask bounce, which we do not find significant) does not produce qualitatively different results.
} 
where the subscript $t$ corresponds to the announcement or non-announcement days in our sample, which are indexed 1 to 72 . To test whether the variance on announcement days is different than on non-announcement days we apply a Levene F-test for each interval $i .^{12}$ Table 2 shows the results.

The ratios of announcement vs. non-announcement days' volatility exhibits a significant spike for the interval $10: 00-10: 05$, which corresponds to the time the LEI index is announced. The increase is not only statistically significant (at the $5 \%$ level), but also economically sizable - volatility increases by an average of 25\%. Before 10:00, there appears to be no overall pattern in the volatility ratio: volatility is about the same on announcement vs. non-announcement days. There is one statistically significant observation at 9:35-9:40 for which announcement days seem to have lower volatility than non-announcement days. After 10:00, the volatility ratios are all above 1, indicating that volatility is overall higher on announcement days in the half hour following the LEI release.

\subsection{Volume}

In this section, we test whether volume is higher on announcement days compared to nonannouncement days in each of the 5-minute intervals in the hour around the announcement. To control for the strong increase in aggregate volume over the sample period and the well known intraday patterns in volume, we create normalized 5-minute volume for each announcement day, $v_{i, t}$, by dividing the volume of the same 5 -minute interval on the matched non-announcement day:

$$
v_{i, t}=\frac{\text { volume } 5 \mathrm{~min} \text { interval } i \text { on announcement day } t}{\text { volume } 5 \text { min interval } i \text { on non-announcement day } t^{\prime}} .
$$

We then regress this normalized volume on a constant for each 5-minute interval from market open at 9:30 until 10:30:

$$
v_{i, t}=\alpha_{i}+\varepsilon_{i, t}, \quad i \in\{9: 30-9: 35,9: 35-9: 40, \ldots, 10: 25-10: 30\}
$$

The null hypothesis we are testing is $\alpha=1$. Column 3 of Table 2 reports the results. At market open the volume on non-announcement days is slightly higher than on non-

\footnotetext{
${ }^{12}$ It is common in empirical work to use modified Levene F-tests (e.g., Brown-Forsythe modified Levenetest), as these are generally more robust to departures from normality of returns. We assume the expected 5 -minute return is equal to zero, which is neither the sample mean, median nor the $10 \%$ trimmed mean, but which empirically turns out to be very close to the median.
} 
TABLE 2

Return Volatility and Volume Ratios

\begin{tabular}{|c|c|c|}
\hline$t_{0}-t_{1}$ & $\begin{array}{c}\text { Volatility Ratio } \\
\quad(p-\text { value })\end{array}$ & $\begin{array}{c}\text { Volume Ratio } \\
\quad(p-\text { value })\end{array}$ \\
\hline $9: 30-9: 35$ & $\begin{array}{l}1.186 \\
(0.23)\end{array}$ & $\begin{array}{l}0.978 \\
(0.46)\end{array}$ \\
\hline $9: 35-9: 40$ & $\begin{array}{c}0.785^{* *} \\
(0.02)\end{array}$ & $\begin{array}{l}1.016 \\
(0.64)\end{array}$ \\
\hline $9: 40-9: 45$ & $\begin{array}{l}0.934 \\
(0.72)\end{array}$ & $\begin{array}{l}1.049 \\
(0.14)\end{array}$ \\
\hline $9: 45-9: 50$ & $\begin{array}{l}1.146 \\
(0.41)\end{array}$ & $\begin{array}{l}1.031 \\
(0.31)\end{array}$ \\
\hline $9: 50-9: 55$ & $\begin{array}{l}0.963 \\
(0.90)\end{array}$ & $\begin{array}{c}1.048 \\
(0.10)^{*}\end{array}$ \\
\hline $9: 55-10: 00$ & $\begin{array}{l}1.179 \\
(0.27)\end{array}$ & $\begin{array}{l}1.046 \\
(0.19)\end{array}$ \\
\hline $10: 00-10: 05$ & $\begin{array}{c}1.252^{* *} \\
(0.05) \\
\end{array}$ & $\begin{array}{c}1.068^{* *} \\
(0.04)\end{array}$ \\
\hline $10: 05-10: 10$ & $\begin{array}{l}1.133 \\
(0.46)\end{array}$ & $\begin{array}{c}1.067^{* *} \\
(0.03)\end{array}$ \\
\hline $10: 10-10: 15$ & $\begin{array}{l}1.037 \\
(0.93)\end{array}$ & $\begin{array}{c}1.070^{* *} \\
(0.03)\end{array}$ \\
\hline $10: 15-10: 20$ & $\begin{array}{c}1.326^{* *} \\
(0.01)\end{array}$ & $\begin{array}{c}1.071^{* *} \\
(0.04)\end{array}$ \\
\hline $10: 20-10: 25$ & $\begin{array}{l}1.017 \\
(0.98)\end{array}$ & $\begin{array}{c}1.071^{* *} \\
(0.02)\end{array}$ \\
\hline $10: 25-10: 30$ & $\begin{array}{l}1.240 \\
(0.10)\end{array}$ & $\begin{array}{c}1.099^{* *} \\
(0.00)\end{array}$ \\
\hline
\end{tabular}

Table 2: Table reports estimates of standard deviation of normalized 5-minute returns and 5-minute volume on announcement and non-announcement days. There are 72 observations in each group. The variance ratio test is a Levene F-test, where zero is assumed to be the median/mean return. The volume ratio is regressed on a constant. The null hypothesis is $\alpha=1$. Standard errors are corrected for heteroskedasticity (White standard errors). One asterisk denotes significance at the 10 percent level, while two asterices denote significance at the 5 percent level in a two-tailed test. 
announcement days, but the difference is insignificant. However, as we get closer to the 10:00 announcement, the volume ratio becomes larger than unity and statistically significant following the announcement, as it was for both returns and volatility. The volume effect, however, persists significantly throughout the half hour following the announcement.

\subsection{Robustness}

To examine the robustness of the results, we repeat the same analysis on the full set of announcement days. Recall that we initially excluded days on which other macro announcements (including Federal Open Market Committee meetings) were released. The full sample consists of 102 announcement days in the sample period January 1997 to August 2005. If the full sample is affected by the presence of other macro announcements, we would expect to find a weaker return response but a stronger volatility and volume responses to the LEI announcements.

We find that the LEI announcement has very similar impact on aggregate stock market returns, volatility and volume, compared with the filtered sample. Specifically, we find that the return response at the time of the announcement (10:00-10:05) is positively related to the change in the LEI, although the coefficient is slightly smaller (0.028) and its statistical significance is weaker (t-statistic of 1.74). This is to be expected as the other announcements are imperfectly correlated with changes in the LEI index and therefore add noise.

In contrast to the return tests which depend on the sign of the announcement, volatility and volume depend on the presence of announcements. Indeed, we find that volatility increases by $28 \%$ following the announcement, which is stronger than for the filtered sample (25\%) where the LEI is the only announcement that occurs. The same applies to trading volume. It increases by $8.8 \%$ following the announcement for the full sample, relative to only $6.8 \%$ in the filtered sample.

\subsection{Discussion of Aggregate Results}

In sum, we show that the LEI announcements have a significant impact on aggregate proxies of information arrival such as returns, return volatility, and trading volume. The effect is short-lived for returns and volatility, consistent with previous studies of the impact of news announcements on aggregate prices. Volume, however, exhibits a more prolonged reaction. These findings are consistent with the presence of investors with limited attention, who find 
it optimal to focus on summary statistics as opposed to the individual components of the index.

The absolute level of the return response is fairly low. However, this result is expected given that limited attention should affect markets less if the information is market-wide, as is the case here (see Peng and Xiong (2006)); investors have a higher incentive to be attentive to information that is more important for their utility, and as a group investors therefore focus more on market-wide information. Further, since the release is recurring and replicable, one would expect attentive arbitrageurs to eliminate profit opportunities arising from the release up to transaction costs. Therefore, the tests in this paper are stacked against the limited attention alternative hypothesis. Our results are thus consistent with both limited attention on the part of a subset of market participants and market efficiency imposed by information gathering incentives and arbitrageurs.

\section{Cross-Sectional Test}

In the previous section, we showed that the release of the LEI has a statistically significant impact on aggregate returns, volatility, and volume. To examine the robustness of the results we test another hypothesis. If the market impact of the LEI announcements are caused by limited attention of a subset of investors, we would expect to find a larger impact on stocks which investors subject to this bias are likely to trade. We test this conjecture by looking at the cross-sectional return response to the LEI release. Inattention-prone investors are more likely to trade large capitalization stocks, which have high volume and are featured more in the news, as noted by Barber and Odean (2005), and 'glamour stocks' (see Lakonishok, Shleifer and Vishny (1994)), which have low book-to-market ratios. Thus, limited attention suggests that large capitalization and low book-to-market ratio stocks should respond more strongly to the release of the LEI. We construct intraday returns for the 25 Fama-French portfolios on the announcement days and show that, consistent with the limited attention effect, the returns of large and low book-to-market stocks respond more to the LEI announcements, compared to small and high book-to-market stocks.

\subsection{Portfolio Construction}

Andersen et al. (2003) suggest that markets respond to macro information very rapidly. In light of that suggestion and in order to increase the power of our tests, we use 1-minute 
returns constructed from tick data on individual stocks. Following the procedure described in Davis, Fama, and French (2000), we obtain the CUSIP numbers of the stocks in each of the 25 portfolios for every month from 1997 to $2005 .{ }^{13}$ Using these data, we then extract from the Trade and Quotes (TAQ) database the transactions of every stock in each portfolio from 9:30 until 10:30 on the LEI announcement days.

Calculation of portfolio returns using tick-by-tick data poses a challenge since many stocks do not trade frequently. As a result, we use the following algorithm. For the time interval (e.g., 10:00 to 10:01), a stock's return is calculated if it traded during that minute and during the preceding minute (9:59 to 10:00). If a stock trades multiple times during both minutes, we use the latest trades in both minutes in order to calculate the return. All the stocks that do not trade during either or both minutes are disregarded. The portfolio return is the equally-weighted return of all the stocks' returns that did trade between these two minutes. Thus, our testing procedure is not affected by stale prices.

Some summary statistics for all 25 portfolios are shown in Table 4 in the Appendix. It is worth pointing out that the average numbers of stocks in our portfolios are consistent with the data provided by Ken French on the daily 5x5 portfolios. Also, note that none of the portfolios have very few stocks trading during the minute when the LEI announcements are made: the minimum is 20 stocks and that is in the large size portfolios, where there is ample liquidity and each stock trades frequently. In the small size portfolios, which might be most subject to liquidity and stale price problems, there are always enough stocks trading between 10:00 and 10:01, the minimum being 54. Lastly, we highlight the fact that the average 1minute returns during the event window (9:30 to 10:30) are not statistically different from zero across all portfolios, which gives us confidence that these high-frequency returns are not biased in any particular way.

\subsection{Tests and Results}

The limited attention hypothesis implies that large and low $\mathrm{B} / \mathrm{M}$ stocks should have a higher announcement effect compared to small and high B/M stocks. In order to test this hypothesis, we use the intradaily $5 \times 5$ Fama-French portfolio returns described above and we perform exactly the same return tests as in the previous section, regressing the return of

\footnotetext{
${ }^{13}$ The only difference between their procedure and ours is due to the fact that we do not have the handcollected data from Moody's Industrial Manuals that were used in Davis, Fama, and French (2000). We do not believe that this creates any systematic bias in our analysis.
} 
TABLE 3

Cross-Sectional Return Regressions

\begin{tabular}{|c|c|c|c|c|c|c|c|}
\hline \multicolumn{8}{|c|}{$R_{i, 10: 00-10: 01}=\alpha_{i}+\beta_{i} \cdot L E I_{t}+\varepsilon_{i, t}$} \\
\hline & \multicolumn{7}{|c|}{ Book-to-Market } \\
\hline & & $\mathbf{L}$ & 2 & 3 & 4 & $\mathbf{H}$ & All B/M \\
\hline & $\mathbf{S}$ & $\begin{array}{l}-0.0147 \\
(0.0127)\end{array}$ & $\begin{array}{c}0.0084 \\
(0.0123)\end{array}$ & $\begin{array}{c}-0.0031 \\
(0.0137)\end{array}$ & $\begin{array}{l}0.0237^{* *} \\
(0.0111)\end{array}$ & $\begin{array}{c}-0.0171 \\
(0.0187)\end{array}$ & $\begin{array}{l}-0.0006 \\
(0.0066)\end{array}$ \\
\hline & 2 & $\begin{array}{c}0.0128 \\
(0.0105)\end{array}$ & $\begin{array}{c}-0.0027 \\
(0.0101)\end{array}$ & $\begin{array}{c}0.0070 \\
(0.0072)\end{array}$ & $\begin{array}{l}0.0096^{* *} \\
(0.0057)\end{array}$ & $\begin{array}{c}0.0101 \\
(0.0081)\end{array}$ & $\begin{array}{c}0.0074 \\
(0.0058)\end{array}$ \\
\hline \multirow[t]{4}{*}{ Size } & 3 & $\begin{array}{c}0.0209^{* *} \\
(0.0087)\end{array}$ & $\begin{array}{c}0.0094 \\
(0.0062)\end{array}$ & $\begin{array}{c}0.0040 \\
(0.0054)\end{array}$ & $\begin{array}{c}0.0032 \\
(0.0055)\end{array}$ & $\begin{array}{c}0.0056 \\
(0.0070)\end{array}$ & $\begin{array}{c}0.0086 \\
(0.0054)\end{array}$ \\
\hline & 4 & $\begin{array}{c}0.0188^{* *} \\
(0.0103)\end{array}$ & $\begin{array}{c}0.0148^{* *} \\
(0.0072)\end{array}$ & $\begin{array}{l}0.0144^{* *} \\
(0.0062)\end{array}$ & $\begin{array}{l}0.0156^{* *} \\
(0.0059)\end{array}$ & $\begin{array}{c}0.0137 \\
(0.0117)\end{array}$ & $\begin{array}{l}0.0154^{* *} \\
(0.0062)\end{array}$ \\
\hline & B & $\begin{array}{c}0.0305^{* *} \\
(0.0113)\end{array}$ & $\begin{array}{c}0.0256^{* *} \\
(0.0082)\end{array}$ & $\begin{array}{c}0.0243^{* *} \\
(0.0087)\end{array}$ & $\begin{array}{c}0.0222^{* *} \\
(0.0072)\end{array}$ & $\begin{array}{c}0.0184^{* *} \\
(0.0089)\end{array}$ & $\begin{array}{l}0.0242^{* *} \\
(0.0077)\end{array}$ \\
\hline & All Sizes & $\begin{array}{l}0.0136^{* *} \\
(0.0080)\end{array}$ & $\begin{array}{l}0.0111^{* *} \\
(0.0055)\end{array}$ & $\begin{array}{c}0.0093 \\
(0.0060)\end{array}$ & $\begin{array}{l}0.0149^{* *} \\
(0.0044)\end{array}$ & $\begin{array}{c}0.0061 \\
(0.0057)\end{array}$ & \\
\hline
\end{tabular}

Table 3: The table reports $\beta_{i}$ coefficient estimates from OLS regressions of return data for each of the 25 Fama-French portfolios from 10:00 to 10:01 on the same-minute LEI announcement. There are 72 observations in each group. The "All B/M" and "All Sizes" portfolios are created by summing the returns of the individual portfolios across rows (B/M) and columns (size), respectively. Returns are multiplied by 100 and standard errors are corrected for heteroskedasticity (White standard errors). The changes in LEI have been normalized to have mean zero and unit variance. Two asterices denote statistical significance at the $5 \%$ level in a two-tailed test.

each portfolio from 10:00 to 10:01 on the normalized change in the LEI:

$$
R_{i, 10: 00-10: 01}=\alpha_{i}+\beta_{i} \cdot \Delta \overline{L E I}_{t}+\varepsilon_{i, t} \quad \text { for all } 72 \text { dates in our sample }
$$

where $R_{i, 10: 00-10: 01}$ is the return of portfolio $i$ from 10:00 to 10:01.

Table 3 shows the results from the above regressions. Three main results emerge from this analysis. First, coefficients are positive for almost all portfolios, consistent with the aggregate results presented in the previous section. Second, for each B/M quintile, as size increases, the regression coefficient $\beta_{i}$ becomes larger, i.e. a larger announcement effect. For instance for the medium B/M category (3), the coefficient goes from being negative and insignificant for small size to being equal to $0.0243 \%$ for large size. This pattern is present 


\section{FIGURE 3}

Size Effect

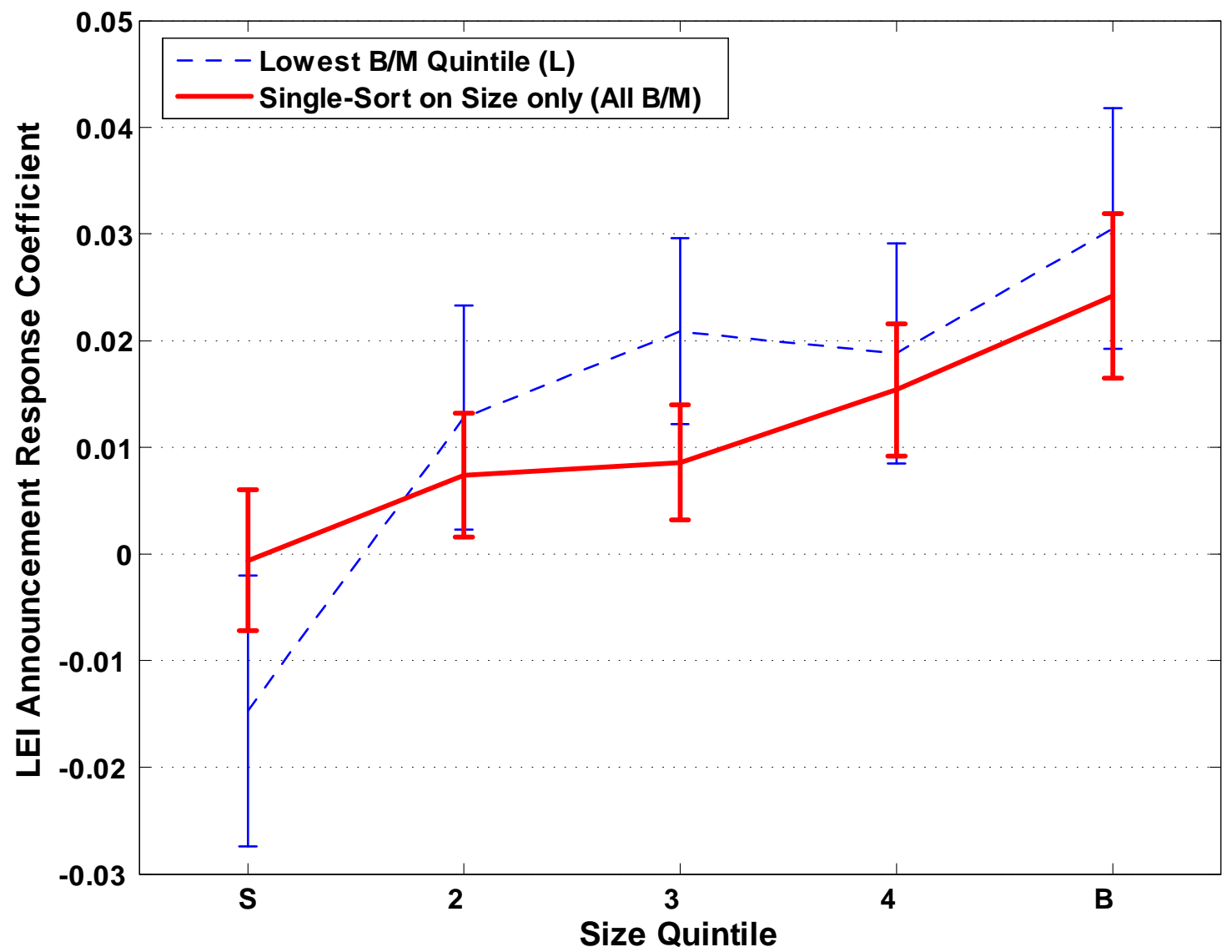

Figure 3: The figure shows the regression coefficients beta, i.e. the LEI announcement effect, for the five lowest $\mathrm{B} / \mathrm{M}$ portfolios (B/M quintile $\mathrm{L}$, dashed line) and for the five portfolios sorted only on size (All B/M, solid line). The robust standard errors are included as error bars. For clarity, we did not include the other $\mathrm{B} / \mathrm{M}$ quintiles on this figure.

in four of the five $\mathrm{B} / \mathrm{M}$ quintiles, and appears to be stronger as $\mathrm{B} / \mathrm{M}$ decreases. We further highlight this size-pattern by constructing aggregate size portfolios by summing the returns across all $\mathrm{B} / \mathrm{M}$ categories (i.e. summing across the rows). This gives us five portfolios sorted only on size. We run the same regressions as before on these five portfolios. The results are shown in the last column of Table $3($ All B/M) and also in Figure 3. The results are clear and significant: as size increases, the portfolios react more and more to the release of the LEI.

The third pattern that emerges from Table 3 is that, as $\mathrm{B} / \mathrm{M}$ increases, the regression coefficient $\beta_{i}$ decreases, i.e. the LEI announcement effect is lower. This B/M-result is present 
for the three largest size quintiles $(3,4$, and $\mathrm{B})$ and is strongest for the largest size quintile (B), where the coefficient decreases from $0.0305 \%$ to $0.0184 \%$ as B/M increases. As before, we further highlight this effect by creating five single-sort portfolios (All Sizes) by summing the returns across size quintiles. We run the same regression as before on these five portfolios sorted on B/M only and the results are shown on the last row of Table 3 (All Sizes) and also in Figure 4. The $\mathrm{B} / \mathrm{M}$ effect is weaker than the size effect, but the evidence suggests that low $\mathrm{B} / \mathrm{M}$ (growth stocks) have higher responses to the release of the LEI than high $\mathrm{B} / \mathrm{M}$ (value stocks).

FIGURE 4

\section{Book-to-Market Effect}

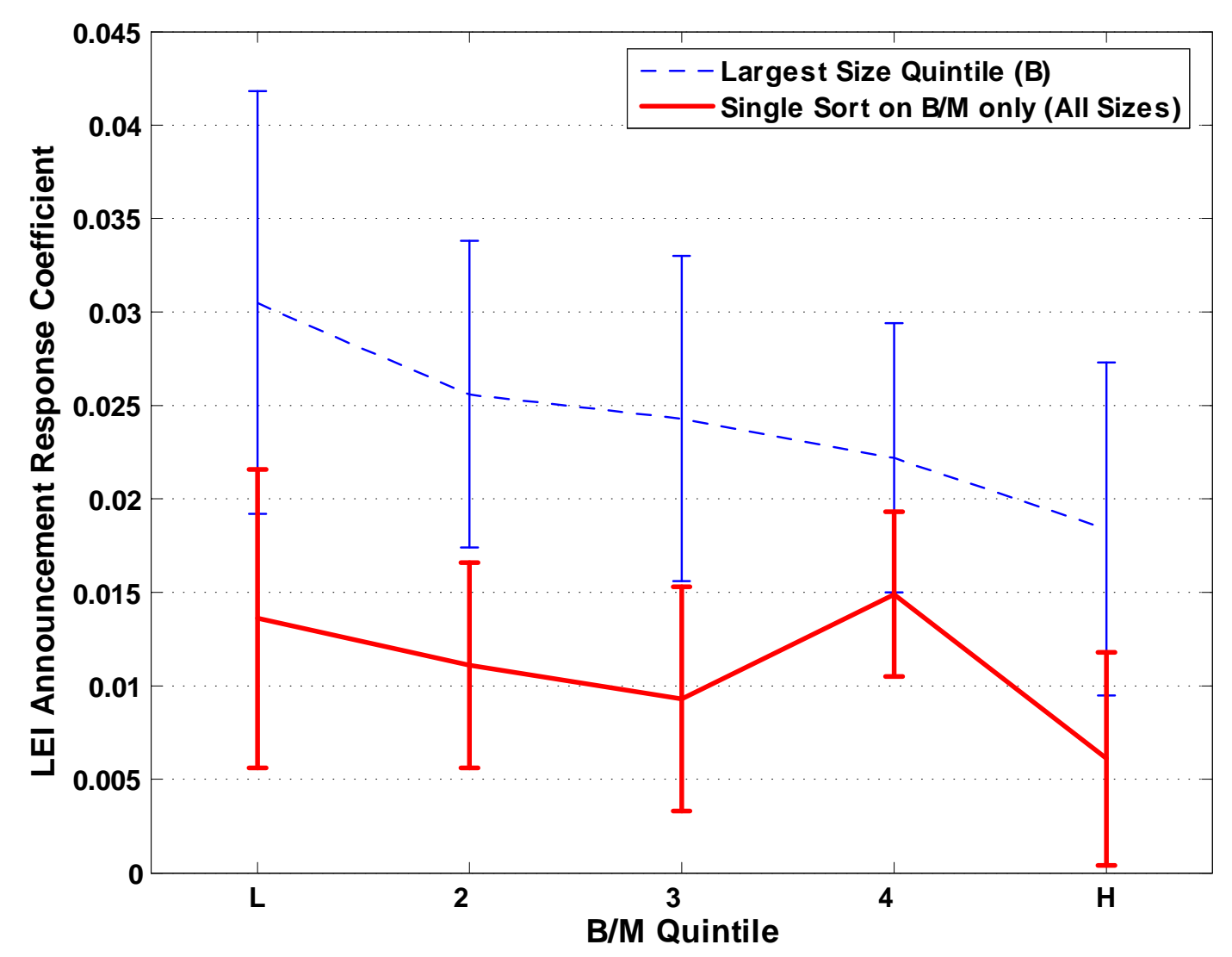

Figure 4: The figure shows the coefficients beta, i.e. the LEI announcement effect, for the five largest size portfolios (size quintile B, dashed line), and for the five portfolios sorted only on B/M (All Sizes, solid line). The robust standard errors are included as error bars. For clarity, we did not include the other size quintiles on this figure.

In sum, large capitalization and low book-to-market stocks respond more strongly to the 
LEI announcement. These are also the stocks that retail investors, who are more likely to be prone to a limited attention bias, trade the most (Barber and Odean (2005)).

\subsection{Liquidity, Bid-Ask Spreads and the Bid-Ask Bounce}

Could the cross-sectional results be explained by differences in liquidity across the portfolios? After all, spreads and bid-ask bounce are higher for small market capitalization stocks. We argue that this would lead us to over-reject the null. To see that, consider a day with a positive LEI announcement. Since prices respond to the announcement, we are likely to observe an increase in orders executed at the ask price. For small stocks, which have large bid-ask spread, the bid-ask bounce would generate "extra" returns compared to large stocks that have smaller bid-ask spreads. As a result, effects related to bid-ask spreads and bounce go against our results.

Another possible explanation for the lower observed announcement response for small stocks is that they are more illiquid compared to large stocks. However, in the construction of the 1-minute returns to the 25 Fama-French portfolios, we only take into account the stocks that trade in both the 9:59 - 10:00 minute and the 10:00-10:01 minute. As a result, stale prices are not an issue for the portfolio returns we construct. In addition, we document in Table 4 in the appendix that there are many stocks trading in each portfolio, so the announcement returns are based on well-diversified portfolios.

\section{Conclusion}

In this paper we present evidence that investors act on summary information, impacting even aggregate stock market returns, volatility and volume. The paper uses a weak restriction on aggregate prices to test for the presence of limited investor attention: Markets should not respond to the release of summary statistics that are based on information already available. We identify a unique stream of releases, the U.S. Leading Economic Index (LEI), that is released on an ongoing basis at pre-determined times, consists of previously published macro data, is calculated using a publicly available methodology, and is widely followed by the mass media. We show that this series has statistically significant effects on proxies for information arrival such as instantaneous market-level returns (which move in the direction of the announcement), return volatility and trading volume.

Since the test pertains to aggregate information, the effects of limited attention on re- 
turns should be constrained by information gathering incentives and arbitrageurs. Peng and Xiong (2006) show that investors with a limited attention budget choose to expend a larger fraction of their resources on aggregate information, such as the index constituents of the LEI. Further, since the LEI is released every month at a pre-determined time and date, it is relatively easy for arbitrageurs to profit from a market return reaction to its release. Therefore, if investors suffer from limited attention, the market return impact should still be small, which is what we find. However, the other proxies for the arrival of information, volatility of volume, increase substantially following the announcement. Thus, the evidence provided in this paper indicates that summary statistics like the LEI are valuable to a significant fraction of investors, even though the information provided is technically stale. More broadly, this suggests a role for other summaries of information such as the ones provided by the financial press (e.g., Meschke (2004)). 


\section{References}

[1] Abarbanell, Jeffery S., and Victor L. Bernard, 1992, Tests of analysts' overreaction/underreaction to earning information as an explanation for anomalous stock price behavior, The Journal of Finance, 3, 1181-1207.

[2] Admati, Anat R., and Paul Pfleiderer, 1988, A theory of intraday patterns: Volume and price variability, Review of Financial Studies, 1, 3 - 40.

[3] Andersen, Torben G., Tim Bollerslev, Francis X. Diebold, and Clara Vega, 2003, Micro effects of macro announcements: Real-time price discovery in foreign exchange, American Economic Review, 79, 1132 - 1145.

[4] Andersen, Torben G., Tim Bollerslev, Francis X. Diebold, and Clara Vega, 2007, Realtime price discovery in stock, bond and foreign exchange markets, Journal of International Economics, forthcoming.

[5] Ball, Ray, and Philip Brown, 1968, An empirical evaluation of accounting income numbers, Journal of Accounting Research, 6, 159-178.

[6] Barber, Brad M. and Terrance Odean, 2005, All that glitters: The effect of attention and news on the buying behavior of individual and institutional investors, Working paper, Haas School of Business, University of California, Berkeley.

[7] Bernard, Victor L., and Jacob K. Thomas, 1989, Post earnings announcement drift: delayed price response or risk premium?, Journal of Accounting Research, Supplement, $29,1-48$.

[8] Bernard, Victor L., and Jacob K. Thomas, 1990, Evidence that stock prices do not fully reflect the implications of current earnings for future earnings, Journal of Accounting and Economics, 13, 305-340.

[9] Burns, A. F., and Mitchell, W. C., 1946, Measuring Business Cycles, New York, NY: National Bureau of Economic Research.

[10] Busse, Jeffrey A., T. Clifton Green, 2002, Market efficiency in real time, Journal of Financial Economics, 65, 415 - 437. 
[11] The Conference Board, 2001, Business Cycle Indicators Handbook, New York, NY: The Conference Board.

[12] Cutler, David M., James M. Poterba, and Lawrence H. Summers, 1989, What moves stock prices?, Journal of Portfolio Management 15, 4 - 12.

[13] Davis, James L., Eugene F. Fama, and Kenneth R. French, 2000, Characteristics, Covariances, and Average Returns: 1929 to 1997, Journal of Finance, 55, 389-406.

[14] De Bondt, Werner F. M., and Richard Thaler, 1985, Does the stock market overreact?, The Journal of Finance, 40, 793-805.

[15] De Bondt, Werner F. M., and Richard Thaler, 1986, Further evidence of investor overreaction and stock market seasonality, The Journal of Finance, 42, 557-581.

[16] DellaVigna S., and Pollet J., 2006, Investor Inattention, Firm Reaction, and Friday Earnings Announcements, Working paper, University of California, Berkeley.

[17] Evans, Martin D. D., Richard K. Lyons, 2004, Do markets absorb news quickly?, Working paper, Haas School of Business, University of California, Berkeley.

[18] Fama, Eugene, 1970, Efficient capital markets: a review of theory and empirical work, Journal of Finance, 25, 383 - 417.

[19] Fama, Eugene, 1991, Efficient Markets II, Fiftieth Anniversary Invited Paper, Journal of Finance, 46, 25 - 44

[20] Fama, Eugene F. and Kenneth R. French, 1992, The cross-section of expected stock returns, Journal of Finance, 47, 427-465.

[21] Fama, Eugene F. and Kenneth R. French, 1993, Common Risk Factors in the Returns on Stocks and Bonds, Journal of Financial Economics, 33, 3-56.

[22] Filardo, A. J., 2004, The 2001 recession: what did recession prediction models tell us? Bank of International Settlements Working Paper No. 148.

[23] Fleming, Michael J., Eli M. Remolona, 1999, Price formation and liquidity in the U.S. Treasury market: The response to public information, Journal of Finance, 54, 1901 1915. 
[24] French, K.R., and R. Roll, 1986, Stock returns variances: the arrival of information and the reaction of traders, Journal of Financial Economics, 17, 5-26.

[25] Hand, John, 1990, A Test of the Extended Functional Fixation Hypothesis, The Accounting Review, 65, 740-763.

[26] Haugen, Robert A., Eli Talmor, and Walter N. Torous, 1991, The effect of volatility on the level of stock prices and subsequent returns, Journal of Finance 46, 985-1007.

[27] Harris, L. 1986, A transaction data study of weekly and intradaily patterns in stock returns, Journal of Financial Economics 16, 99-118.

[28] Hirshleifer, David, Sonya Lim, and Siew Hong Teoh, 2006, Driven to Distraction: Extraneous Events and Underreaction to Earnings News, mimeo.

[29] Huberman, Gur, and Tomer Regev, 2001, Contagious speculation and a cure for cancer: A nonevent that made stock prices soar, The Journal of Finance 56, 387-396.

[30] Huberman, Gur, and J. William Schwert, 1985, Information Aggregation, Inflation and the Pricing of Indexed Bonds, Journal of Political Economy, 93, 92-114.

[31] Jegadeesh, Narasimhan, and Sheridan Titman, 1995, Overreaction, delayed reaction and contrarian profits, Review of Financial Studies, 8, 973-993.

[32] Lakonishok J., Shleifer A. and Vishny R.W, 1994, Contrarian Investment, Extrapolation, and Risk, The Journal of Finance, 5, 1541-1578.

[33] Lehman, Bruce M., 1990, Fads, martingales, and market efficiency, The Quarterly Journal of Economics, 1, 1-28.

[34] Liew, J. and M. Vassalou, 2000, Can book-to-market, size and momentum be risk factors that predict economic growth?, Journal of Financial Economics, 57, 221-245.

[35] McGuckin, R. H., Ozyildirim, A., and Zarnowitz, V., 2001, The Composite Index of Leading Economic Indicators: How to Make It More Timely, Working Paper No. 8430, National Bureau of Economic Research: Cambridge, MA.

[36] McGuckin, R. H., Ozyildirim, A., and Zarnowitz, V., 2007, A More Timely and Useful Index of Leading Indicators, Journal of Business and Economic Statistics, January 2007. 
[37] Meschke, J. Felix, 2004, CEO Interviews on CNBC, Working Paper, Arizona State University

[38] Mitchell, Mark, and Harold Mulherin, 1994, The Impact of Public Information on the Stock Market, The Journal of Finance 49, 923-950.

[39] Peng, Lin and Wei Xiong, 2006, Investor Attention, Overconfidence and Category Learning, Journal of Financial Economics, 80, 563-602.

[40] Rashes, Michael, 2001, Massively Confused Investors Making Conspicuously Ignorant Choices (MCI-MCIC), The Journal of Finance 56, 1911-1927.

[41] Roll, Richard, 1988, $\mathrm{R}^{2}$, The Journal of Finance, 43, 541-566.

[42] Schwert, G. William, 1981, The adjustment of stock prices to information about inflation, Journal of Finance, 36, 15-29.

[43] Schwert, G. William, 1989, Why does stock market volatility change over time?, Journal of Finance, 44, 1115-1153.

[44] Shiller, Robert, 1981, Do stock prices move too much to be justified by subsequent changes in dividends?, American Economic Review, 71, 421-436.

[45] Shleifer, Andrei, 2000, Inefficient market: an introduction to behavioral finance, Oxford University Press.

[46] Sloan, Richard G., 1996, Do stock prices fully reflect information in accruals and cash flows about future earnings?, The Accounting Review, 71, 289-315.

[47] Wood, R.A., T.H. McInish, and J.K. Ord. 1985, An investigation of transactions data for NYSE stocks, The Journal of Finance, 40, 723-739.

[48] Zarnowitz, Victor, 1992, Business Cycles: Theory, History, Indicators, and Forecasting, The University of Chicago Press: Chicago, IL, 316-356.

[49] Zhang, Lu, 2006, Anomalies, NBER working paper 11322. 


\section{Appendix: LEI Calculation}

Let $\Delta L E I_{t, t-1}$ denote the monthly change in the LEI for month $t-1$ published in month $t$. This monthly change is calculated as the sum of component contributions which are derived from a symmetric percent change formula:

$$
\Delta L E I_{t, t-1}=\left(\sum_{i=1}^{10} \sigma_{i} * 200 * \frac{X_{i, t}-X_{i, t-1}}{X_{i, t}+X_{i, t-1}}\right)
$$

where $\sigma_{i}$ is the standardization factor calculated by dividing the inverse standard deviation of component $i$ by the sum of the inverse standard deviations over all components. As the notation makes clear, the index published in month $t$ refers to past data for $t-1$ which has already been published.

Since January 2001, leading indicator components for month $t-1$ that are not available at the time of publication, month $t$, are estimated by The Conference Board using a univariate autoregressive model to forecast each unavailable component. This procedure seeks to address the problem of varying availability in its components (i.e. publication lags). Without it, the index would contain incomplete components or it would not be available promptly under the current schedule.

In the publication schedule prior to January 2001, the index published in month $t$ referred to the month $t-2$. In the new schedule after January 2001, the index published in month $t$ refers to the preceding month $t-1$ (this information is available from The Conference Board). For example, in the old publication schedule the index would be calculated in the first week of March $(t)$ for January $(t-2)$, and the January value of the LEI would use a complete set of components. According the new schedule, the index is calculated in the third week of March for February $(t-1)$, and the February value of the index uses $70 \%$ of the components which are already available and remaining $30 \%$ are forecast. As seen in this example, users of the LEI would have had to wait for two more weeks until April for the February index.

Specifically, the missing components (Manufacturers' New Orders for Consumer Goods and Materials, Manufacturers' New Orders for Nondefense Capital Goods, and the personal consumption expenditure used to deflate the Money Supply (M2) are estimated using a time series regression that uses two lags (see McGuckin et al. (2001) for more on this model and a comparison with other alternative lags structures). ${ }^{14}$ When the unavailable data become

\footnotetext{
${ }^{14}$ The procedure used to estimate the current month's personal consumption expenditure deflator (used
} 
available in the next month, the index is revised.

The missing components could be forecast through alternative means. However, The Conference Board has focused on simplicity, stability, and low costs of production and argues for concentrating on easily implemented autoregressive model. Note that under the pre-2001 release schedule of the LEI, it would have been possible to perfectly forecast the new value each month if the costs of data collection and application of the index methodology calculation were undertaken. In the post-2001 schedule, this is still possible, but the estimated components require an additional step.

in the calculation of real money supply and commercial and industrial loans outstanding) incorporates the current month's consumer price index when it is available before the release of the U.S. Leading Economic Indicators. 
TABLE 4

Descriptive Statistics of the Intradaily Fama-French Portfolios

\begin{tabular}{|c|c|c|c|c|}
\hline Portfolio \# & $\bar{r}_{1-\min }(\%)$ & $\sigma_{1-\min }(\%)$ & $\bar{N}_{\text {portfolio }}$ & $\bar{N}_{t, L E I}$ \\
\hline 1 & -0.00617 & 0.19262 & 580 & 93 \\
\hline 2 & -0.00409 & 0.24114 & 433 & 59 \\
\hline 3 & -0.00354 & 0.20421 & 505 & 54 \\
\hline 4 & -0.00408 & 0.22387 & 675 & 55 \\
\hline 5 & 0.00337 & 0.20218 & 960 & 69 \\
\hline 6 & -0.00372 & 0.10093 & 201 & 82 \\
\hline 7 & -0.000737 & 0.10228 & 156 & 62 \\
\hline 8 & 0.00282 & 0.13706 & 158 & 54 \\
\hline 9 & 0.0037 & 0.15862 & 149 & 49 \\
\hline 10 & 0.01208 & 0.61251 & 91 & 30 \\
\hline 11 & -0.00028 & 0.10274 & 163 & 91 \\
\hline 12 & -0.00174 & 0.07271 & 119 & 62 \\
\hline 13 & 0.000509 & 0.07263 & 105 & 53 \\
\hline 14 & 0.00196 & 0.08177 & 82 & 41 \\
\hline 15 & 0.0015 & 0.09624 & 47 & 24 \\
\hline 16 & -0.00227 & 0.07047 & 138 & 102 \\
\hline 17 & 0.00108 & 0.1789 & 100 & 68 \\
\hline 18 & 0.00244 & 0.12944 & 78 & 50 \\
\hline 19 & 0.000728 & 0.05695 & 54 & 35 \\
\hline 20 & 0.000566 & 0.08681 & 36 & 19 \\
\hline 21 & -0.000876 & 0.07975 & 158 & 144 \\
\hline 22 & 0.00164 & 0.1503 & 78 & 63 \\
\hline 23 & -0.000564 & 0.0771 & 50 & 37 \\
\hline 24 & 0.000232 & 0.05572 & 36 & 28 \\
\hline 25 & -0.000134 & 0.06687 & 28 & 20 \\
\hline
\end{tabular}

Table 4: For each of the 25 Fama-French portfolios, we report the average 1-minute returns $\bar{r}$ over the hour from 9:30 to 10:30 along with the respective standard deviations of returns $\sigma$. We also report the average number of stocks in each portfolio $\bar{N}_{\text {portfolio }}$ and the average number of stocks $\bar{N}_{t, L E I}$ trading from 10:00 to 10:01 in each portfolio. All these summary statistics are for our entire dataset of 72 dates spanning from February 1997 to August 2005. Note that the idiosyncratic nature of the returns and standard deviations of portfolio 10 seem to be due to an error in the TAQ data that we are investigating. Nevertheless, we can confirm that this potential error does not occur between 10:00 and 10:01. 